\title{
Comparative Study on Impacts of Power Curve Model on Capacity Factor Estimation of Pitch-Regulated Turbines
}

\author{
MH Albadi*a and EF El-Saadanyb \\ a Department of Electrical and Computer Engineering,, College of Engineering, Sultan Qaboos University, P.O Box 33, \\ Postal Code 123, Al-Khoud, Muscat, Sultanate of Oman \\ ${ }^{b}$ Department of Electrical and Computer Engineering, University of Waterloo, 200 University Ave. W, Waterloo, ON, \\ N2L3G1,Canada
}

Received 31 October 2010; accepted 11 January 2012

\begin{abstract}
The amount of energy produced by a turbine depends on the characteristics of both wind speed at the site under investigation and the turbine's power performance curve. The capacity factor (CF) of a wind turbine is commonly used to estimate the turbine's average energy production. This paper investigates the effect of the accuracy of the power curve model on CF estimation. The study considers three CF models. The first CF model is based on a power curve model that underestimates the turbine output throughout the ascending segment of the power curve. To compensate for the aforementioned discrepancy, the Weibull parameters, $\mathrm{c}$ and $\mathrm{k}$, which are used to describe wind profile, are calculated based on cubic mean wind speed (CMWS). The second CF model is based on the most accurate generic power curve model available in open literature. The third CF model is based on a new model of power performance curve which mimics the behavior of a typical pitch-regulated turbine curve. As the coefficients of this power curve model are based on a general estimation of the turbine output at different wind speeds, they can be further tuned to provide a more accurate fit with turbine data from a certain manufacturer.
\end{abstract}

Keywords: Wind power, Turbine curve modelling, Capacity factor estimation

$$
\begin{aligned}
& \text { دراسة أثر نموذج منحنى الأداء على تقدير معامل قدرة التوربينات }
\end{aligned}
$$

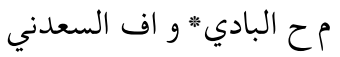

الملخص: تعتمد كمية الطاقة التي تنتجها مولدات طاقة الرياح على خصائص كل من سرعة الرياح في الموقع قيد التحقيق ومنحنى أداء قدرة

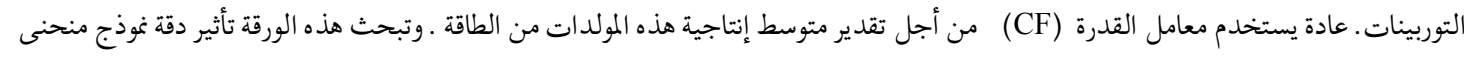

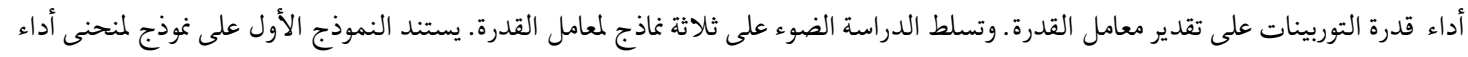

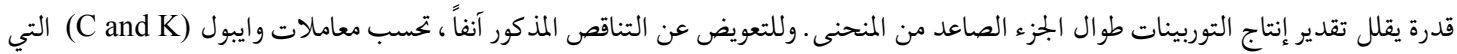

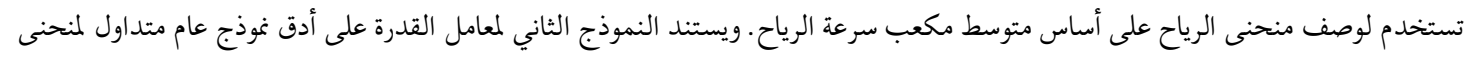

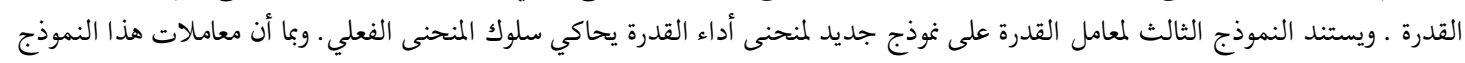

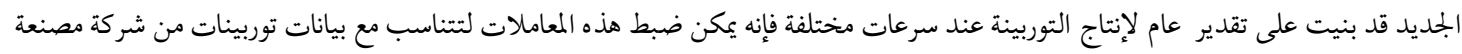

معينة.

الكلمات المفتاحية: طاقة الرياح، نماذج منحنى أداء قدرة التوربينات، تقدير معامل القدرة

\section{Introduction}

Despite wind power's intermittent nature, strong growth has occurred in its frequency of install action because of environmental concerns about other sources of electricity, and because of developments in wind turbine technologies. Due to wind speed variability, a wind turbine rarely operates at its rated output. Therefore, the capacity factor (CF) of a turbine is com-

$\overline{\text { *Corresponding author's e-mail: mbadi@squ.edu.om }}$ monly used to estimate its average energy production, which in turn can be used for the economic appraisal of wind power projects at potential sites. Moreover, CF models can be used by manufacturers and wind power project developers for optimum turbine-site matching, and for the ranking of potential sites (TaiHer and Li 2008; Rau and Jangamshetti 2001; Jangamshetti and Rau 2001; Salameh and Safari 1992; Jangamshetti and Rau 1999). 
The amount of energy produced by a turbine depends on the characteristics of both wind speed at the site under investigation and the turbine's power performance curve. Wind speed at any site is commonly modeled by the Weibull probability density function (pdf), which is characterized by two parameters: the scale factor, $c$, and the shape factor, $k$. The turbine's power performance curve can be described by three parameters: cut-in, nominal, and cut-out speeds. This paper presents a novel model to estimate the CF of modern pitch-regulated wind turbines, based on a new turbine's power performance curve and the Weibull parameters of wind speed. An early version of this paper was published in Albadi and El-Saadany (2009).

After this introduction, the paper proceeds with a literature survey devoted to wind power output modeling, which includes wind speed modeling, turbine output modeling, and the existing CF model. A new power curve model is then proposed in section III. In section IV, the two new CF models are derived, and a case study is presented in section V. Finally, conclusions are presented.

\section{Wind Power Modeling}

\subsection{Wind Speed Modeling}

Wind speed is commonly modeled by the 2-parameter Weibull pdf shown in the following formula:

$$
f(v)=\frac{k}{c}\left(\frac{v}{c}\right)^{k-1} e^{-\left(\frac{v}{c}\right)^{k}}
$$

where $v$ is the wind speed in $\mathrm{m} / \mathrm{s} ; k$ is the shape factor, and $c$ is the scale factor. The shape factor, $k$, is related to the variance of the wind speed; therefore, it is location specific. The Weibull parameters can be obtained using the mean and the standard deviation of wind speed at the chosen site. The mean wind speed (MWS) can be calculated using the following formula:

$$
\bar{v}=\int_{0}^{\infty} v f(v) d t
$$

The above equation can be written as follows.

$$
\bar{v}=c \Gamma\left(1+\frac{1}{k}\right)
$$

where $\Gamma$ is the complete gamma function given by

$$
\Gamma(a)=\int_{0}^{\infty} t^{a-1} e^{-t} d t
$$

The standard deviation of wind speed measurements is calculated using the following equation.

$$
\sigma=\sqrt{\frac{\sum_{i=1}^{N} f_{i}\left(v_{i}-\bar{v}\right)^{2}}{\sum_{i=1}^{N} f_{i}}}
$$

The above formula can be written as follows:

$$
\sigma=c \sqrt{\Gamma\left(1+\frac{2}{k}\right)-\Gamma^{2}\left(1+\frac{1}{k}\right)}
$$

Knowing the mean and standard deviation of wind speed data at the potential site, one can estimate the two parameters of the Weibull function by solving (3) and (6) iteratively.

\subsection{Turbine Output Modeling}

The power output of a wind turbine is given as follows:

$$
P(v)=\frac{1}{2} C_{p} \rho A v^{3}
$$

where $P(v)$ is wind turbine output power; $\rho$ is the air density in kilograms per cubic meter $\left(\mathrm{kg} / \mathrm{m}^{3}\right)$; $\mathrm{A}$ is the swept rotor area in square meters $\left(\mathrm{m}^{2}\right)$, and $C_{p}$ is the turbine coefficient of performance. The power curve of a pitch-regulated wind turbine is characterized by three speeds: cut-in, nominal, and cut-out speeds. When the wind speed is below the cut-in speed $\left(V_{c}\right)$, the output power is zero, and the rotor cannot be loaded. At its nominal speed, $\left(V_{r}\right)$, the power output is at the rated value $\left(P_{r}\right)$. In response to the power control mechanisms, the power output remains constant as wind speed increases until the cut-out speed $\left(V_{f}\right)$, at which point the turbine will be turned off to prevent mechanical damage. Therefore, Eqn. 7 can be written as follows:

$$
P(v)=P_{r}\left\{\begin{array}{cc}
0 & v<V_{c} \text { or } v>V_{f} \\
P_{a s c}(v) & V_{c} \leq v<V_{r} \\
1 & V_{r} \leq v \leq V_{f}
\end{array}\right.
$$

where $P_{a s c}(v)$ is wind turbine output power throughout the ascending segment of the power curve. An example of a turbine output is presented in Figure 1. For this specific turbine Vestas turbine $V_{c}, V_{r}$, and $V_{f}$ take

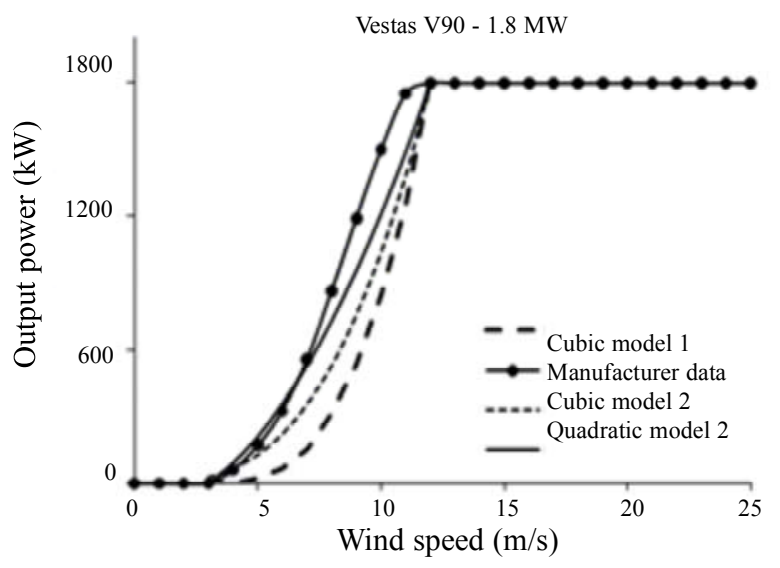

Figure 1. A graphical comparison of the quadratic and cubic models 
values of 3,12 , and $25 \mathrm{~m} / \mathrm{s}$, respectively.

Between $V_{c}$ and $V_{r}$, the turbine output increases as wind speed increases. Manufacturer data show a point of inflection in the ascending segment of the power curve. This point indicates that the turbine efficiency experiences a change at this point. Despite the single point of inflection in the ascending power curve segment, $C_{p}$ is not constant for most of the speed range. This phenomenon is demonstrated in Figure 2, in which the $C_{p}$ and power output of Nordex N90-2300 are presented.

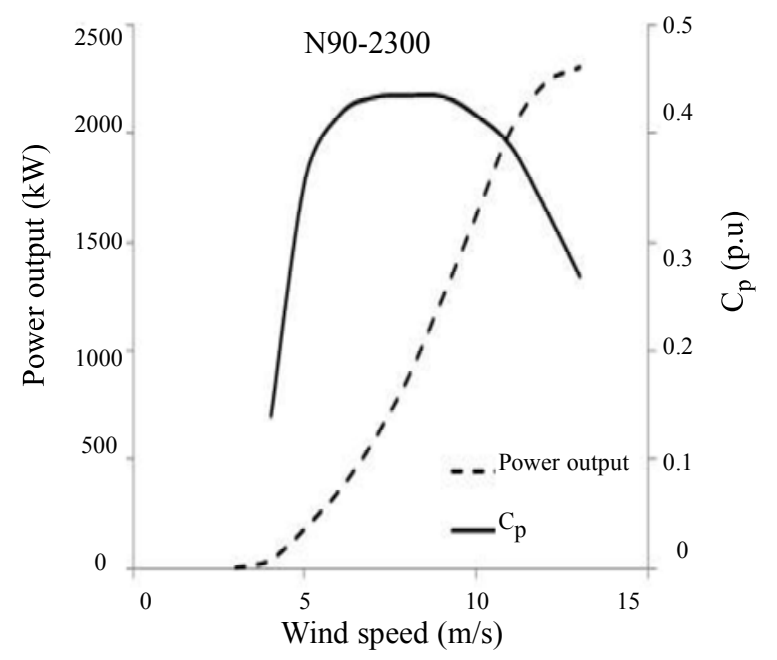

Figure 2. Coefficient of performance $\left(\mathrm{C}_{\mathrm{p}}\right)$ of N90-2300

Although the $C_{p}$ is unique for each turbine and, as a result, is difficult to generalize, there have been some attempts to represent the ascending segment of the power curve with a generic model. Generic here means that a turbine's output, as a percentage of rated power, is described using the cut-in and nominal speeds only, without requiring the specific turbine output throughout the ascending segment. Generic models available in open literature include linear, quadratic, and cubic ones. Below is a brief description of each model:

1) The linear model assumes a linear increase in the turbine output between the cut-in and the nominal speeds. This model, generally, overestimates wind potential. The linear model is given by the following equation:

$P_{\text {asc }}(v)=\frac{v-V_{c}}{V_{c}-V_{r}}$

2) Cubic model 1 implicitly assumes a constant overall efficiency of the turbine throughout the ascending segment of the power curve. This model is given by the following formula (Dialynas and Machias 1989):

$$
P_{a s c}(v)=\frac{\left(v-V_{c}\right)^{3}}{\left(V_{r}-V_{c}\right)^{3}}
$$

3) Cubic model 2, considered by Jangamshetti and Rau (1999) and Salameh and Safari (1992) is very similar to Cubic model 1 . The only difference is the absence of $V_{c}$ from this model. cubic model 2 is given by the following equation:

$P_{a s c}(v)=\frac{v^{3}}{V_{r}^{3}}$

4) Quadratic model 1 was originally proposed by Justus et al. (1976), and its coefficients were calculated by Giorsetto and Utsurogi (1983). These coefficients were determined based on the assumption that the output of the turbine follows the cubic model, Eq. 10, between $\left(V_{c}+V_{r}\right) / 2$ and $V_{r}$ (Justus et al. 1976).

$P_{a s c}(v)=a_{0}+a_{1} v+a_{2} v^{2}$

5) Quadratic model 2, presented by Pallabazzer (1995), does not have the $\left(a_{1} v\right)$ term of the previous model.

$$
P_{a s c}(v)=\frac{v^{2}-V_{c}^{2}}{V_{r}^{2}-V_{c}^{2}}
$$

As demonstrated in Figure 1 and Table I, the quadratic model presented in Pallabazzer (1995) is the most accurate generic model to represent manufacturer data throughout the ascending segment of the power curve; therefore, it is used in the derivation of one of the two $\mathrm{CF}$ models proposed in this paper.

A better representation of manufacturer data can be achieved by using a higher order polynomial function as described by the following equation, where $n$ is the order of the polynomial function:

$$
P_{a s c}(v)=\sum_{0}^{n} a_{n} v^{n}
$$

However, due to the unique and nonlinear behavior of $C_{p}$, the coefficients, an, are turbine specific and difficult to generalize. The authors in Chang and Tu (2007) and Celik (2003) use a third order polynomial function to represent the turbine output in the ascending power curve segment, and regression is used to find the coefficients $\left(a_{n}\right)$. For the manufacturer data presented in Figure 1 and Table I, the polynomial coefficients take values of $0.5734,-0.3537,0.0639$, and 0.0026 for $a_{0}, a_{1}, a_{2}$, and $a_{3}$, respectively. 
Table 1. Comparison of different models for V90-3MW

\begin{tabular}{|c|c|c|c|c|c|c|c|}
\hline \multirow[b]{2}{*}{ Speed } & \multirow[b]{2}{*}{ pdf* } & \multicolumn{6}{|c|}{ Turbine output (kW) } \\
\hline & & $\begin{array}{r}\text { Data } \\
{[8]}\end{array}$ & $\begin{array}{l}\text { Linear } \\
\text { model }\end{array}$ & $\begin{array}{r}\text { Cubic } \\
\text { model } 1\end{array}$ & $\begin{array}{r}\text { Cubic } \\
\text { model } 2\end{array}$ & $\begin{array}{r}\text { Quadratic } \\
\text { model } 1\end{array}$ & $\begin{array}{r}\text { Quadratic } \\
\text { model } 2\end{array}$ \\
\hline 3 & 0.1076 & 0 & 0 & 0 & 0 & 0 & 0 \\
\hline 4 & 0.1231 & 100 & 250 & 2 & 57 & -10 & 97 \\
\hline 5 & 0.1264 & 250 & 500 & 14 & 111 & 27 & 222 \\
\hline 6 & 0.1194 & 400 & 750 & 47 & 192 & 111 & 375 \\
\hline 7 & 0.1049 & 625 & 1000 & 111 & 305 & 243 & 556 \\
\hline 8 & 0.0864 & 925 & 1250 & 217 & 455 & 422 & 764 \\
\hline 9 & 0.0671 & 1275 & 1500 & 375 & 648 & 648 & 1000 \\
\hline 10 & 0.0492 & 1650 & 1750 & 595 & 889 & 922 & 1264 \\
\hline 11 & 0.0343 & 2075 & 2000 & 889 & 1183 & 1243 & 1556 \\
\hline 12 & 0.0226 & 2475 & 2250 & 1266 & 1536 & 1611 & 1875 \\
\hline 13 & 0.0142 & 2750 & 2500 & 1736 & 1953 & 2027 & 2222 \\
\hline 14 & 0.0085 & 2920 & 2750 & 2311 & 2439 & 2490 & 2597 \\
\hline $15-25$ & 0.0100 & 3000 & 3000 & 3000 & 3000 & 3000 & 3000 \\
\hline \multicolumn{2}{|c|}{ Annual yield (MWh) } & 5475 & 6934 & 1979 & 3122 & 2848 & 4536 \\
\hline \multicolumn{2}{|c|}{$\%$ Error } & & $26.7 \%$ & $-63.9 \%$ & $-43.0 \%$ & $-48.0 \%$ & $-17.1 \%$ \\
\hline
\end{tabular}

* Based on MWS $=6 \mathrm{~m} / \mathrm{s}$ and $\mathrm{k}=2$

\subsection{Capacity Factor Modeling}

The average power produced by a wind turbine can be calculated by integrating the power curve model multiplied by the Weibull function represented by Eqn. (1).

$$
P_{\text {ave }}=\int_{0}^{\infty} P(v) f(v) d v
$$

The capacity factor is the ratio between the average and the rated power of the turbine. The authors in Jangamshetti and Rau (1999), Salameh and Safari (1992) used cubic model 2, represented by Eqn. (11), the CF model can be written as follows:

$$
C F=\frac{P_{a v e}}{P_{r}}=\frac{1}{V_{r}^{3}} \int_{V_{c}}^{V_{r}} v^{3} f(v) d v+\int_{V_{r}}^{V_{f}} f(v) d v
$$

Jangamshetti and Rau (2001) compared the values of the CF obtained from (16) to the measured ones, and found that the model significantly underestimated wind potential at the site under study. To compensate for the mismatch between the modeled and the measured values, Jangamshetti and Rau (2001) investigated the effect of using the root mean square wind speed (RMSWS) and the CMWS to estimate the Weibull function parameters of the wind profile. Jangamshetti and Rau (2001) found that using the CMWS resulted in a better estimation of the $C F$, at the site under study than when using the original (arithmetic) MWS and the RMSWS. The MRSWS and CMWS are defined by the following formulas:

$$
\begin{aligned}
& \bar{v}_{C M W S}=\sqrt[3]{\frac{\sum_{i=1}^{N} f_{i} v_{i}^{3}}{\sum_{i=1}^{N} f_{i}}} \\
& \bar{v}_{R M S W S}=\sqrt[2]{\frac{\sum_{i=1}^{N} f_{i} v_{i}^{2}}{\sum_{i=1}^{N} f_{i}}}
\end{aligned}
$$

However, when one compares the original wind profile, obtained using the arithmetic MWS, with that obtained using the RMSWS or the CMWS, a significant difference in the profile is observed (Albadi and El-Saadany 2010). Actually, using the RMSWS or the CMWS shifts the original wind speed data towards higher values, as illustrated in Figure 3.

Tai-Her and Li (2008) solved the integral presented in (16) and devised a CF model as a function of the main turbine curve parameters, $V_{c}, V_{r}$, and $V_{f}$, and the two parameters of the Weibull function, $c$ and $k$, that are obtained based on the CMWS.

$$
\begin{aligned}
& C F=\left(\frac{V_{c}}{V_{r}}\right)^{3} e^{-\left(\frac{V_{c}}{c}\right)^{k}}-e^{-\left(\frac{V_{f}}{c}\right)^{k}} \\
& +\frac{3 \Gamma\left(\frac{3}{k}\right)}{k\left(\frac{V_{r}}{c}\right)^{3}}\left[\gamma\left(\left(\frac{V_{r}}{c}\right)^{k}, \frac{3}{k}\right)-\gamma\left(\left(\frac{V_{c}}{c}\right)^{k}, \frac{3}{k}\right)\right]
\end{aligned}
$$




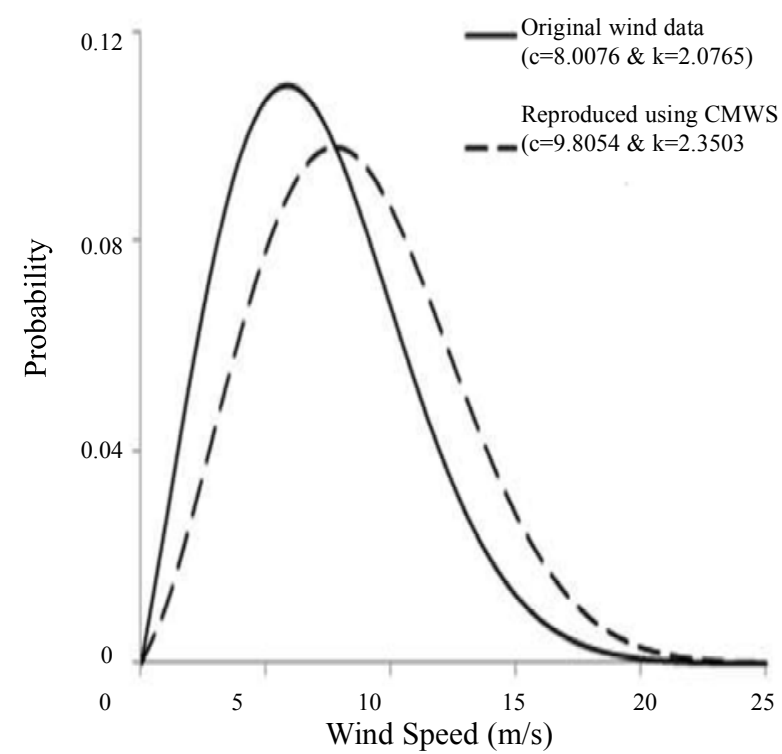

Figure 3. The effect of using the CMWS to obtain $c$ and $k$ (data are from)

where $\gamma$ is the lower incomplete gamma function given by

$$
\gamma(u, a)=\frac{1}{\Gamma(a)} \int_{0}^{u} x^{a-1} e^{-x} d x
$$

\section{Proposed Power Curve Model}

Figures 4 to 6 present examples of the power curve of pitch-regulated turbines from three manufacturers, Vestas, Fuhrlander, and the National Renewable Energy Laboratory. Similar to Figure 2, all turbine curves show their point of inflection in the second half of the ascending segment. This point is attributable to the decrease in turbine efficiency after it has reached its maximum value. Because none of existing power curve models consider this property, all of them underestimate the power curve in the second half of the ascending segment.

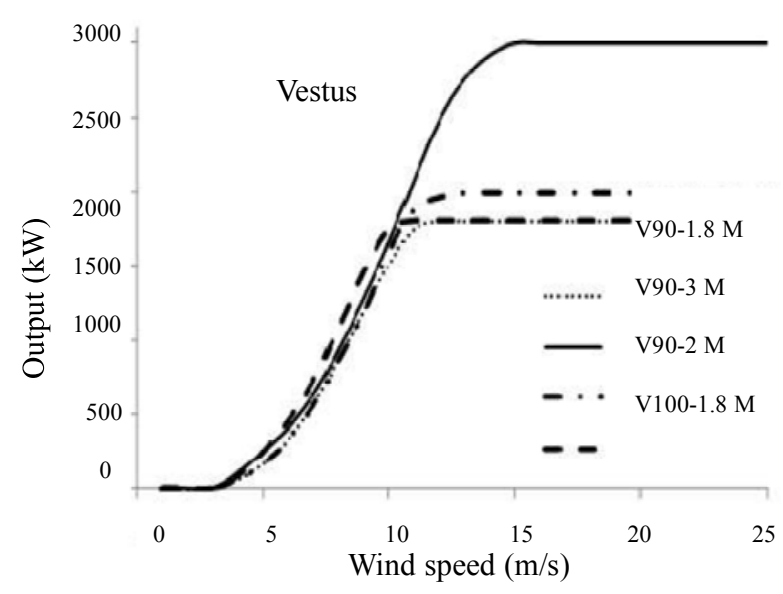

Figure 4. Vestus pitch-regulated turbines

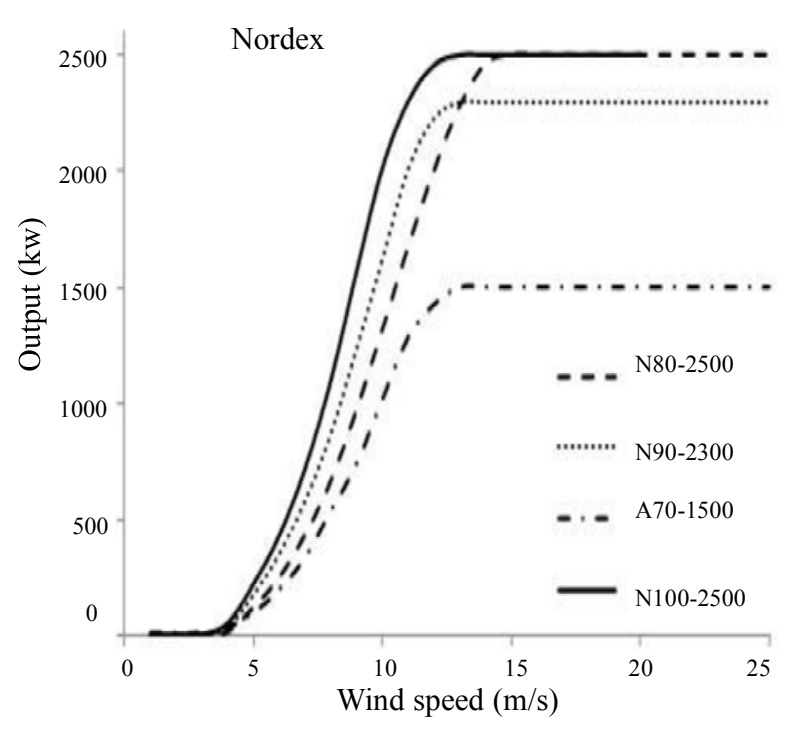

Figure 5. Nordex pitch-regulated turbines

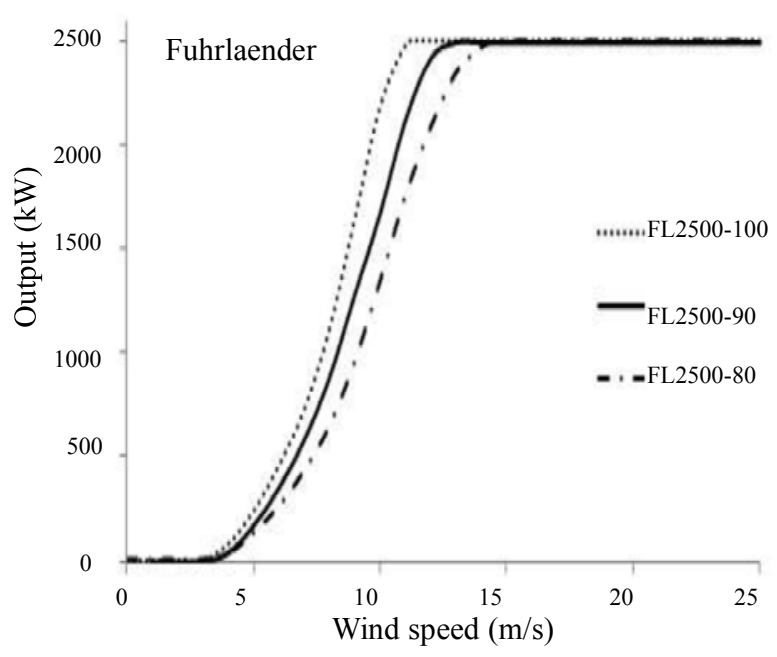

Figure 6. Fuhlaender pitch-regulated turbines

For a more accurate representation of the ascending segment of the power curve, a four order polynomial function is proposed in Eqn. 14. The coefficients, $a_{0}$ to $a_{4}$, of the polynomial function are obtained by solving the following equations:

$$
\begin{aligned}
& P\left(V_{c}\right)=0 \\
& P\left(V_{r}\right)=1 \\
& P\left(V_{1}\right)=0.03 \\
& P\left(V_{2}\right)=0.4 \\
& P\left(V_{3}\right)=0.75 \\
& P\left(v_{4}\right)=0.97
\end{aligned}
$$

where 


$$
\begin{aligned}
& V_{1}=V_{c}+0.1\left(V_{r}-V_{c}\right) \\
& V_{2}=V_{c}+0.5\left(V_{r}-V_{c}\right) \\
& V_{3}=V_{c}+0.75\left(V_{r}-V_{c}\right) \\
& V_{4}=V_{c}+0.9\left(V_{r}-V_{c}\right)
\end{aligned}
$$

Normalized turbine curves for different cut-in and nominal speeds are presented in Table 2. An example of the proposed power curve model is presented in Figure 7, and a comparison of the proposed model and quadratic model 2 for turbines with $V_{c}=3 \mathrm{~m} / \mathrm{s}$ and $V_{r}$ $=13 \mathrm{~m} / \mathrm{s}$ is presented in Figure 8 . As the coefficients of this model are based on a general estimation of turbine output at different wind speeds, they can be further tuned to obtain a better fit of turbine data from a certain manufacturer.

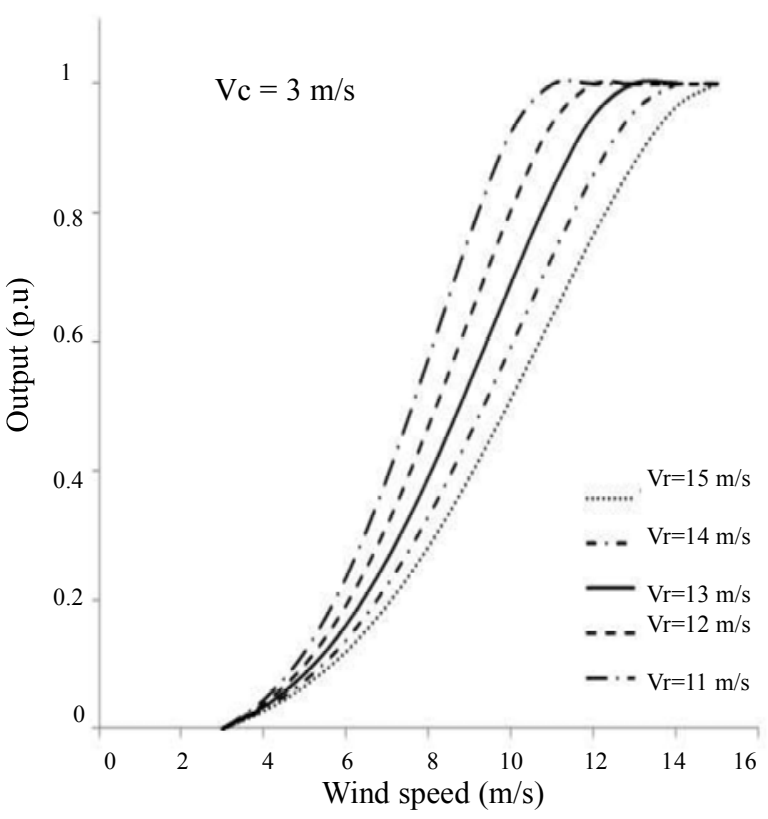

Figure 7. Proposed model when the cut-in speed is $3 \mathrm{~m} / \mathrm{s}$ and different nominal speeds

From Figure 8, one can conclude that although the power curve in the ascending segment is turbine specific, the proposed model represents manufacturer data better than quadratic model 2 , which is the best generic model available in open literature. For V90-1.8 turbine data, presented in Table I, the error in annual energy estimation of the proposed model is about $0.3 \%$.

\section{New Capacity Factor Model}

Based on the new power curve model proposed in the previous section, the new CF model for pitch-regulated wind turbines is given by the following equation.

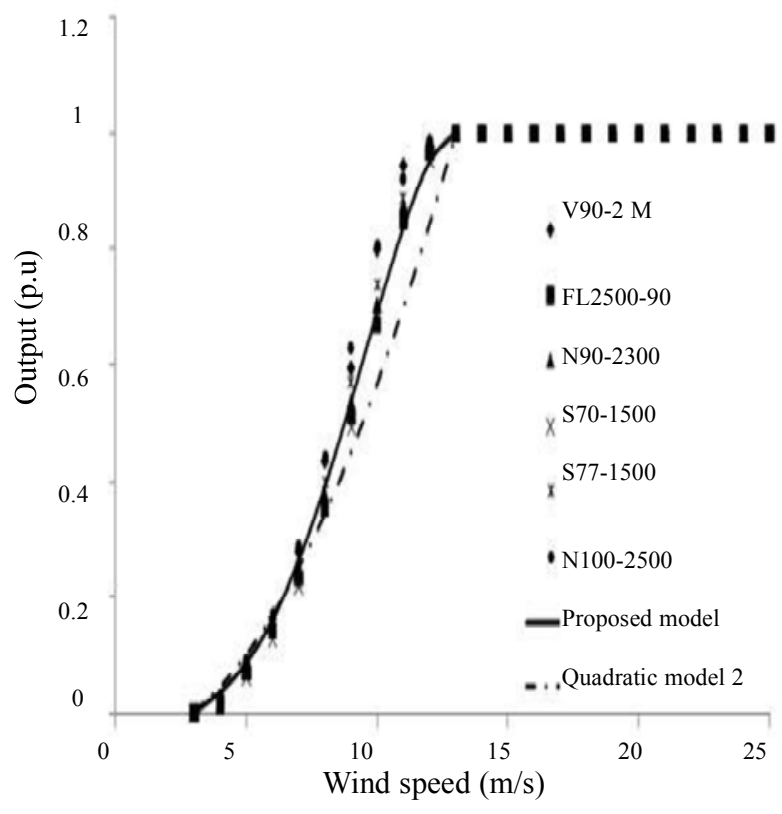

Figure 8. Proposed model versus quadratic model turbine with $V_{c}=3 \mathrm{~m} / \mathrm{s}$ and $V_{r}=13 \mathrm{~m} / \mathrm{s}$

$$
\begin{aligned}
C F=\frac{P_{\text {ave }}}{P_{r}}=a_{0} \int_{V_{c}}^{V_{r}} f(v) d v & +\sum_{n=1}^{4} a_{n} \int_{V_{c}}^{V_{r}} f(v) d v \\
& +\int_{V_{r}}^{V_{f}} f(v) d v
\end{aligned}
$$

where $f(v)$ is the Weibull pdf, given in (1), and its parameters are based on the MWS rather than the CMWS.

Using integration by substitution and by parts (Bird 2003), the new CF model is derived as described by Albadi and El-Saadany (2010).

$$
\begin{aligned}
C F= & e^{-\left(V_{r} / c\right)^{k}}-e^{-\left(V_{f} / c\right)^{k}}+a_{0}\left(e^{-\left(V_{c} / c\right)^{k}}\right)-e^{-\left(V_{r} / c\right)^{k}} \\
& +\sum_{n=1}^{4} a_{n}\left(V_{c}{ }^{n} e^{-\left(\frac{V_{c}}{c}\right)^{k}}-V_{r}{ }^{n} e^{\left.-\left(\frac{V_{r}}{c}\right)^{k}\right)}\right. \\
& +a_{n} \frac{n c^{n}}{k} \Gamma\left(\frac{n}{k}\right)\left(\gamma\left(\left(\frac{V_{r}}{c}\right)^{k}, \frac{n}{k}\right)-\gamma\left(\left(\frac{V_{c}}{c}\right)^{k}, \frac{n}{k}\right)\right)
\end{aligned}
$$

Equation (23) can be simplified as follows:

$$
\begin{aligned}
C F= & \sum_{n=0}^{4} a_{n} V_{c}^{n} e^{-\left(V_{c} / c\right)^{k}}+\left(1-\sum_{n=0}^{4} a_{n} V_{r}^{n}\right) e^{-\left(V_{r} / c\right)^{k}}-e^{-\left(V_{f} / c\right)^{k}} \\
& +\sum_{n=1}^{4} a_{n} \frac{n c^{n}}{k} \Gamma\left(\frac{n}{k}\right)\left(\gamma\left(\left(\frac{V_{r}}{c}\right)^{k}, \frac{n}{k}\right)-\gamma\left(\left(\frac{V_{c}}{c}\right)^{k}, \frac{n}{k}\right)\right)
\end{aligned}
$$


Table 2. Normalized turbine curves for different turbines characgterized by cut-in $\left(V_{c}\right)$ and nominal speed $\left(V_{r}\right)$ based on the proposed power curve model

\begin{tabular}{|c|c|c|c|c|c|}
\hline$V_{c}$ & 2 & 2 & 2 & 2 & 2 \\
\hline$V_{r}$ & 11 & 12 & 13 & 14 & 15 \\
\hline 2 & 0 & 0 & 0 & 0 & 0 \\
\hline 3 & 0.0391 & 0.0343 & 0.0305 & 0.0275 & 0.0249 \\
\hline 4 & 0.1006 & 0.0861 & 0.0751 & 0.0665 & 0.0597 \\
\hline 5 & 0.1926 & 0.1615 & 0.1383 & 0.1205 & 0.1065 \\
\hline 6 & 0.3180 & 0.2640 & 0.2236 & 0.1926 & 0.1684 \\
\hline 7 & 0.4718 & 0.3919 & 0.3309 & 0.2836 & 0.2465 \\
\hline 8 & 0.6416 & 0.5388 & 0.4569 & 0.3919 & 0.3400 \\
\hline 9 & 0.8073 & 0.6929 & 0.5947 & 0.5134 & 0.4467 \\
\hline 10 & 0.9410 & 0.8376 & 0.7341 & 0.6416 & 0.5624 \\
\hline 11 & 1 & 0.9513 & 0.8613 & 0.7677 & 0.6811 \\
\hline 12 & 1 & 1 & 0.9592 & 0.8802 & 0.7953 \\
\hline 13 & 1 & & 1 & 0.9654 & 0.8955 \\
\hline 14 & 1 & 1 & 1 & 1 & 0.9704 \\
\hline 15 & 1 & 1 & 1 & 1 & 1 \\
\hline$V c$ & 3 & 3 & 3 & 3 & 3 \\
\hline$V r$ & 11 & 12 & 13 & 14 & 15 \\
\hline 3 & 0 & 0 & 0 & 0 & 0 \\
\hline 4 & 0.0454 & 0.0391 & 0.0343 & 0.0305 & 0.0275 \\
\hline 5 & 0.1205 & 0.1006 & 0.0861 & 0.0751 & 0.0665 \\
\hline 6 & 0.2358 & 0.1926 & 0.1615 & 0.1383 & 0.1205 \\
\hline 7 & 0.3919 & 0.3180 & 0.2640 & 0.2236 & 0.1926 \\
\hline 8 & 0.5772 & 0.4718 & 0.3919 & 0.3309 & 0.2836 \\
\hline 9 & 0.7677 & 0.6416 & 0.5388 & 0.4569 & 0.3919 \\
\hline 10 & 0.9272 & 0.8073 & 0.6929 & 0.5947 & 0.5134 \\
\hline 11 & 1 & 0.9410 & 0.8376 & 0.7341 & 0.6416 \\
\hline 12 & 1 & 1 & 0.9513 & 0.8613 & 0.7677 \\
\hline 13 & 1 & 1 & 1 & 0.9592 & 0.8802 \\
\hline 14 & 1 & 1 & 1 & 1 & 0.9654 \\
\hline 15 & 1 & 1 & 1 & 1 & 1 \\
\hline$V_{c}$ & 4 & 4 & 4 & 4 & 4 \\
\hline$V r$ & 11 & 12 & 13 & 14 & 15 \\
\hline 4 & 0 & 0 & 0 & 0 & 0 \\
\hline 5 & 0.0541 & 0.0454 & 0.0391 & 0.0343 & 0.0305 \\
\hline 6 & 0.1491 & 0.1205 & 0.1006 & 0.0861 & 0.0751 \\
\hline 7 & 0.2981 & 0.2358 & 0.1926 & 0.1615 & 0.1383 \\
\hline 8 & 0.4955 & 0.3919 & 0.3180 & 0.2640 & 0.2236 \\
\hline 9 & 0.7146 & 0.5772 & 0.4718 & 0.3919 & 0.3309 \\
\hline 10 & 0.9080 & 0.7677 & 0.6416 & 0.5388 & 0.4569 \\
\hline 11 & 1 & 0.9272 & 0.8073 & 0.6929 & 0.5947 \\
\hline 12 & 1 & 1 & 0.9410 & 0.8376 & 0.7341 \\
\hline 13 & 1 & 1 & 1 & 0.9513 & 0.8613 \\
\hline 14 & 1 & 1 & 1 & 1 & 0.9592 \\
\hline 15 & 1 & 1 & 1 & 1 & 1 \\
\hline
\end{tabular}


Because $P\left(V_{c}\right)=0$ and $P\left(V_{r}\right)=1 \mathrm{pu}$, the above equation could be further simplified as follows:

$$
\begin{aligned}
C F & =-e^{-\left(V_{f} / c\right)^{k}} \\
& +\sum_{n=1}^{4} a_{n} \frac{n c^{n}}{k} \Gamma\left(\frac{n}{k}\right)\left(\gamma\left(\left(\frac{V_{r}}{c}\right)^{k}, \frac{n}{k}\right)-\gamma\left(\left(\frac{V_{c}}{c}\right)^{k}, \frac{n}{k}\right)\right)
\end{aligned}
$$

The above equation is independent of $a_{0}$ and can be used for any higher order polynomial representation of the power curve. For sites at which wind profile is represented by a Raleigh distribution function $(k=2)$, the scale factor, $c$, can be approximated by the following equation:

$$
c=1.12 \bar{v}
$$

Therefore, Eq. (25) can be written as follows:

$$
C F=-e^{-\left(V_{f} / 1.12 \bar{v}\right)^{2}}+\sum_{n=1}^{4} a_{n} \frac{n(1.12 \bar{v})^{n}}{2} \Gamma\left(\frac{n}{2}\right)\left(\begin{array}{c}
\gamma\left(\left(\frac{V_{r}}{1.12 v}\right)^{2}, \frac{n}{2}\right) \\
-\gamma\left(\left(\frac{V_{c}}{1.12 v}\right)^{2}, \frac{n}{2}\right)
\end{array}\right)
$$

Similarly, the CF model based on quadratic model 2 can be calculated by substituting $a_{1}=a_{3}=a_{4}=0$, and $a_{2}=1 /\left(V_{r}^{2}-V_{c}^{2}\right)$ in Eqn. 26

$$
\begin{aligned}
C F=-e^{-\left(V_{f} / c\right)^{k}}+\frac{1}{V_{r}^{2}-V_{c}^{2}} \frac{2 c^{2}}{k} \\
\Gamma\left(\frac{2}{k}\right)\left(\gamma\left(\left(\frac{V_{r}}{c}\right)^{k}, \frac{2}{k}\right)-\gamma\left(\left(\frac{V_{c}}{c}\right)^{k}, \frac{2}{k}\right)\right)
\end{aligned}
$$

\section{Case Study}

The power curve parameters, represented by $V_{c}, V_{r}$, and $V_{f}$, of 12 different turbines are presented in Table 3 . Using both the existing and the proposed models, seven wind speed scenarios, presented in Table 4, are used to calculate the $\mathrm{CF}$ for each turbine. In Table 5, the CF of each turbine is calculated using the three models.

From Table 4, one can make the following observations and draw certain tentative conclusions:

1. Due to the accuracy of the proposed power curve model over that of quadratic model 2 , the CF val- ues calculated using the CF model that is based on quadratic model 2 of the turbine curve Eqn. 27 is always lower than those obtained using the CF model that is based on the proposed power curve model (Eqn. 25) for all turbines.

2. Although the existing model Eqn. 19 is based on cubic model 2, which underestimates turbine output as demonstrated in Table I, CF values calculated using Eqn. 27, are always lower than those obtained using the existing CF model, for MWS scenarios of 6 and $9 \mathrm{~m} / \mathrm{s}$. This result is attributable to the fact that the existing model is based on CMWS. Using CMWS to estimate the Weibull function parameters shifts the original wind speed data towards higher values, as illustrated in Figure 3. Additionally, CF values obtained using Eqn. 25 are often lower than those calculated using the existing CF model Eqn. 19 due to the same reason.

3. For an MWS scenario of $12 \mathrm{~m} / \mathrm{s}$, using the CMWS in Eqn. 19 for CF calculation resulted in lower CF values for most turbines than the values calculated using Eqns. 25 and 27. This phenomenon is attributable to the fact that using the CMWS in the existing model results in estimating more non-captured wind energy than actually happens. This is due to wind speeds exceeding $\mathrm{V}_{f}$. Thus, the value of the $\mathrm{CF}$ estimated using the existing model peaks at 10 $\mathrm{m} / \mathrm{s}$, Figure 9.

\section{Conclusions}

The existing CF model is based on a cubic model for turbine output, which underestimates the turbine output throughout the ascending segment of the power curve. To compensate for this mismatch, CMWS is commonly used to estimate the Weibull function parameters. This paper demonstrates that the use of CMWS shifts the original wind speed data towards higher values. As a result, the existing CF model tends to overestimate the $\mathrm{CF}$ values for sites with low wind speeds and underestimate the values for other sites with high wind speeds.

This paper presents two new CF models. The first one is based on an existing power curve model that yields a better estimation of the turbine output in the ascending segment of the power curve. The other proposed CF model is based on a new power curve model. The coefficients of this power model are calculated based on a general estimation of the turbine output at different wind speeds; therefore, they can be further tuned to obtain a better fit with turbine data from specific manufacturers. Applications of the proposed models include wind power potential and turbine-site matching studies. 
Table 3. Turbines used in the case study

\begin{tabular}{|c|c|c|c|c|}
\hline $\begin{array}{c}\text { Serial } \\
\text { number }\end{array}$ & $V_{c}$ & $V_{r}$ & $V_{f}$ & Examples \\
\hline $\mathrm{T} 1$ & 2 & 12 & 21 & G58-850 [19] \\
\hline $\mathrm{T} 2$ & 2 & 14 & 21 & G90-2M [19] \\
\hline $\mathrm{T} 3$ & 3 & 11 & 20 & V100-1.8 M [7] \\
\hline $\mathrm{T} 4$ & 3 & 11.5 & 20 & GE1.5XLE [20] \\
\hline T5 & 3 & 11.5 & 25 & FL2500-100 [16] \\
\hline T6 & 3 & 12 & 25 & V90-1.8M [7] \\
\hline $\mathrm{T} 7$ & 3 & 13 & 20 & $\mathrm{~N} 100-2500[8]$ \\
\hline $\mathrm{T} 8$ & 3 & 13 & 25 & N90-2300, S77-1500, and S70-1500[8], V90-2M [7], FL2500-90 [16] \\
\hline T9 & 3 & 14 & 25 & G87-2M [19], G52-850 [19] \\
\hline $\mathrm{T} 10$ & 3 & 14 & 24 & GE1.5SLE [20] \\
\hline T11 & 3 & 14.5 & 25 & FL2500-80 $[16]$ \\
\hline $\mathrm{T} 12$ & 3 & 15 & 25 & G80-2M [19], N80-2500 [8], V90-3M [7] \\
\hline
\end{tabular}

Table 4. Wind speed characteristics

\begin{tabular}{cccccc}
\hline \multicolumn{3}{c}{ Original Data } & \multicolumn{3}{c}{ Using CMWS } \\
MWS & $\mathrm{c}$ & $\mathrm{k}$ & CMWS & $\mathrm{c}$ & $\mathrm{k}$ \\
\hline 6 & 6.770 & 2 & 7.444 & 8.402 & 2.307 \\
7 & 7.899 & 2 & 8.682 & 9.800 & 2.301 \\
8 & 9.027 & 2 & 9.903 & 11.178 & 2.297 \\
9 & 10.155 & 2 & 11.064 & 12.490 & 2.292 \\
10 & 11.284 & 2 & 12.114 & 13.675 & 2.284 \\
11 & 12.412 & 2 & 13.012 & 14.690 & 2.267 \\
12 & 13.541 & 2 & 13.742 & 15.516 & 2.237 \\
\hline
\end{tabular}

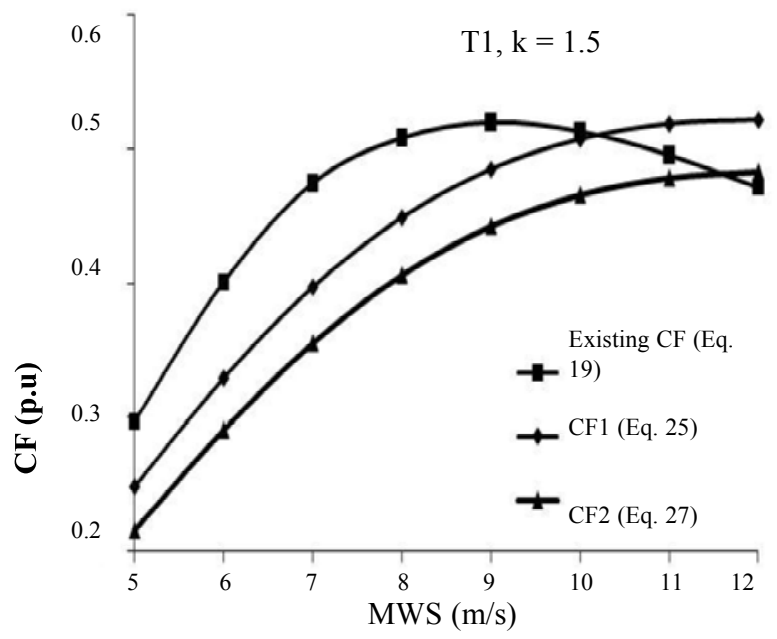

Figure 9. CF of T1 for different MWS scenarios

Table 5. CF calculation using different models for different wind speed scenarios

\begin{tabular}{cccc}
\hline \multicolumn{4}{c}{ MWS $=6 \mathrm{~m} / \mathrm{s}, \mathrm{k}=2$} \\
& CF1 & CF2 & Existing \\
& Eq. 25 & Eq. 27 & Eq. 19 \\
\hline T1 & 0.332 & 0.286 & 0.331 \\
T2 & 0.260 & 0.215 & 0.232 \\
T3 & 0.329 & 0.307 & 0.378 \\
T4 & 0.308 & 0.285 & 0.348 \\
T5 & 0.308 & 0.285 & 0.349 \\
T6 & 0.288 & 0.264 & 0.321 \\
T7 & 0.251 & 0.228 & 0.269 \\
T8 & 0.251 & 0.228 & 0.270 \\
T9 & 0.221 & 0.198 & 0.226 \\
T10 & 0.221 & 0.198 & 0.226 \\
T11 & 0.207 & 0.185 & 0.207 \\
T12 & 0.195 & 0.173 & 0.189 \\
\hline
\end{tabular}

\begin{tabular}{cccc}
\hline & \multicolumn{3}{c}{ MWS $=9 \mathrm{~m} / \mathrm{s}, \mathrm{k}=2$} \\
& CF1 & CF2 & Existing \\
& Eq. 25 & Eq. 27 & Eq. 19 \\
\hline T1 & 0.569 & 0.538 & 0.598 \\
T2 & 0.566 & 0.512 & 0.577 \\
T3 & 0.565 & 0.532 & 0.622 \\
T4 & 0.547 & 0.514 & 0.574 \\
T5 & 0.544 & 0.509 & 0.598 \\
T6 & 0.502 & 0.463 & 0.548 \\
T7 & 0.484 & 0.422 & 0.474 \\
T8 & 0.483 & 0.445 & 0.501 \\
T9 & 0.462 & 0.421 & 0.499 \\
T10 & 0.461 & 0.419 & 0.495 \\
T11 & 0.443 & 0.401 & 0.475 \\
T12 & 0.425 & 0.381 & 0.451 \\
\hline
\end{tabular}

\begin{tabular}{cccc}
\hline \multicolumn{4}{c}{ MWS $=12 \mathrm{~m} / \mathrm{s}, \mathrm{k}=2$} \\
& CF1 & CF2 & Existing \\
& Eq. 25 & Eq. 27 & Eq. 19 \\
\hline T1 & 0.690 & 0.660 & 0.692 \\
T2 & 0.673 & 0.641 & 0.677 \\
T3 & 0.640 & 0.594 & 0.582 \\
T4 & 0.639 & 0.602 & 0.643 \\
T5 & 0.627 & 0.600 & 0.565 \\
T6 & 0.610 & 0.580 & 0.550 \\
T7 & 0.605 & 0.564 & 0.607 \\
T8 & 0.595 & 0.554 & 0.586 \\
T9 & 0.588 & 0.545 & 0.588 \\
T10 & 0.573 & 0.516 & 0.508 \\
T11 & 0.572 & 0.526 & 0.569 \\
T12 & 0.559 & 0.522 & 0.501 \\
\hline
\end{tabular}




\section{References}

Albadi MH, El-Saadany EF (2010), New method for estimating $\mathrm{CF}$ of pitch-regulated wind turbines. Electric Power Systems Research 80:1182-1188.

Albadi MH, El-Saadany EF (2009), Effect of power curve model accuracy on CF estimation of pitchregulated turbines. CIGRÉ Canada Conference on Power Systems, Toronto, Ontario, Canada.

Bird J (2003), Engineering Mathematics. Elsevier Newnes.

Celik AN (2003), Energy output estimation for smallscale wind power generators using Weibull-representative wind data. J. of Wind Engineering and Industrial Aerodynamics 91:693-707.

Chang TJ, Tu YL (2007), Evaluation of monthly capacity factor of WECS using chronological and probabilistic wind speed data: A case study of Taiwan. Renewable Energy 32:1999-2010.

Dialynas EN, Machias AV (1989), Reliability modeling interactive techniques of power systems including wind generating units. Archiv Fuer Elektrotechnik 72:33-41.

Giorsetto P, Utsurogi KF (1983), Development of a new procedure for reliability modeling of wind turbine generators. Power Apparatus and Systems. IEEE transactions on PAS-102:134-143.
Jangamshetti SH, Rau VG (2001), Normalized power curves as a tool for identification of optimum wind turbine generator parameters. IEEE transaction on Energy Conversion 16:283.

Jangamshetti SH, Rau VG (1999), Site matching of wind turbine generators: a case study. IEEE Transaction on Energy Conversion 14:1537-1543.

Jangamshetti SH, Rau VG (2001), Optimum sitting of wind turbine generators. IEEE Transaction on Energy Conversion 16:8-13.

Justus CG, Hargraves WR, Yalcin A (1976), Nationwide assessment of potential output from wind-powered generators. J. of Applied Meteorology 15:

Pallabazzer R (1995), Evaluation of wind-generator potentiality. Solar Energy 55:49-59.

Salameh ZM, Safari I (1992), Optimum windmill-site matching. IEEE Transaction on Energy Conversion 7:669-676.

Tai-Her Y, Li W (2008), A study on generator capacity for wind turbines under various tower heights and rated wind speeds using weibull distribution. IEEE Transaction on Energy Conversion 23: 592602. 